\title{
The Exploration of Drawings as a Tool to Gain Entry to Students' Epistemological Beliefs
}

\author{
Jeremy Briell, Jan Elen, Fien Depaepe, \\ Geraldine Clarebout
}

\author{
Center for Instructional Psychology and Technology, \\ Katholieke Universiteit Leuven
}

\section{Belgium}

Correspondence: Jeremy Briell. Center for Instructional Psychology and Technology. Vesaliusstraat 2 box 3770. Leuven. B-3000 Belgium. E-mail: jeremy.briell@student.kuleuven.be

(C) Education \& Psychology $\mathrm{I}+\mathrm{D}+\mathrm{i}$ and Editorial EOS (Spain) 


\begin{abstract}
Introduction. While there is a general agreement on the theoretical importance of epistemological beliefs, the research area is struggling with the measurement of these beliefs. In this contribution, the use of drawings to ascertain epistemological beliefs is explored.

Method. Three studies are described. In Study 1, we asked participants to draw "knowledge." A two-level categorization system was devised. The coding system was refined through Studies 2 and 3. In Study 2 participants were not only asked to draw "knowledge" but also to provide an oral explanation. In Study 3 the drawings of knowledge were complemented with a written explanation of the drawing.
\end{abstract}

Results. Students conveyed "knowledge" as Internal entities, these could be formal or encompassing or left unspecified, as External objects that are material or material and persons, and as a Combination of internal entities and external object with one-way or two-way interaction or no interaction between them.

Discussion and Conclusion. The three studies reveal that drawings can be a useful tool for exploring students' epistemological beliefs, a tool best accompanied with explanations.

Keywords: personal epistemology, epistemological beliefs, drawings, metacognition, beliefs

Received: 04/29/10 Initial Acceptance: 04/30/10 Definitive Acceptance: 06/03/10 


\section{Exploración de los dibujos como vía de acceso a las creencias epistemológicas de los alumnos}

\section{Resumen}

Introducción. Si bien existe consenso sobre la importancia de las creencias epistemológicas desde un punto de vista teórico, en el campo de la investigación aún se debate la mejor manera de medir estas creencias. Esta contribución explora el uso de dibujos para determinar creencias epistemológicas.

Método. A continuación se describen tres estudios. En el estudio 1 se pidió a los participantes que dibujaran "conocimiento". Los dibujos se categorizaron utilizando un sistema de clasificación de dos niveles. El sistema de codificación se perfeccionó en los estudios 2 y 3 . En el estudio 2 se pidió a los participantes no sólo que dibujaran "conocimiento", sino que además proporcionaran una explicación oral a sus dibujos. En el estudio 3 los participantes acompañaron los dibujos de una explicación escrita.

Resultados. Los estudiantes describieron "conocimiento "como Entidades internas, que a su vez podían ser formales o globales o sin especificar, como Objetos externos que podían ser materiales o materiales y personas, o como una Combinación de entidades internas y objetos externos, con interacción unilateral, bilateral, o sin interacción entre los distintos elementos.

Discusión y Conclusiones. Los tres estudios revelan que los dibujos pueden ser una herramienta útil para estudiar las creencias epistemológicas de los alumnos, sobre todo si se acompañan de explicaciones.

Palabras Clave: epistemología personal, creencias epistemológicas, dibujos, metacognición, creencias

Recibido: 29/04/10 Aceptación Inicial: 30/04/10 Aceptación Definitiva: 03/06/10 


\section{Introduction}

Cognitive and educational researchers are particularly keen to understand the abstract beliefs that students have about the nature of knowledge and knowing, referred to here as epistemological beliefs. One of the major issues with this research is the measurement of those beliefs, which is the overiding impetus for the creative approach explored in this paper.

Interest in epistemological beliefs stems from the fact that they have long been thought to have powerful influences in mediating students' thinking and learning. For instance, King and Kitchener (1994) concluded that epistemological beliefs develop in step with judgments about ill-structured problems. Kuhn (1991) determined that students with absolutist beliefs (i.e., a view of knowledge as an objective entity) are less likely to demonstrate argumentative skills than those holding evaluative beliefs (i.e., an understanding that acknowledges uncertainty without rejecting evaluation). Schommer (1990) found the belief that knowledge is certain (Certainty of knowledge) to negatively correlate with reading comprehension, metacomprehension, and interpretation of information and Schommer, Crouse, and Rhodes (1992) determined the belief that knowledge exists in disconnected forms (Simple knowledge) to adversely affect performance on a mastery test and accurate assessment of comprehension of a mathematical text. More recent studies provide additional evidence that favorable epistemological beliefs (i.e., ones deemed more sophisticated or better developed) are beneficial to academic performance (e.g., Bendixen \& Hartley, 2003; Cano, 2005; Lodewyk, 2007; Peng \& Fitzgerald, 2006; Phan, 2008b; Schommer-Aikins, Duehl, \& Hutter, 2005; Trautwein \& Lüdtke, 2007).

Notwithstanding, significant theoretical differences do exist. There are atleast four major theoretical frameworks for conceiving epistemological beliefs, each implying differing cognitive forms, cognitive ranges, manifestations, and forms of development. Traditionally, epistemological beliefs were modeled as unitary beliefs about knowledge in general that develop in stage-like fashion and exhibit fairly consistent manifestations across domains and contexts (e.g., Baxter Magolda, 1992; Belenky, Clinchy, Goldberger, \& Tarule, 1986; King and Kitchener, 1994; Perry, 1970; Phan, 2008a). Later theorists (i.e., Hofer \& Pintrich, 1997; Schommer 1990), discerned certain dimensions were evident in these earlier models. And, in a significant break from traditional theoretical frameworks, Schommer asserted that the dimensions were relatively independent and could develop asynchronously. Hofer and Pintrich 
proposed a third framework, that of a theory-like structure, hoping to accomodate both the unitary, stage-like framework and the dimensional, asynchronous framework. Meanwhile, researchers increasingly suspect that epistemological beliefs are relative to certain domains or academic disciplines (e.g., Hammer, 1994; Hofer, 2000; Kuhn, Cheney, \& Weinstock, 2000). Notwithstanding, research of specific cognitive ranges did not result in a major theoretical break until recently. Hammer and colleagues (Hammer \& Elby, 2002, Louca, Elby, Hammer, \& Kagey, 2004; Rosenberg, Hammer, \& Phelan, 2006) argued that epistemological beliefs actually exist as fine-grained cognitive resources that are context sensitive in their activation. Each framework is more complex than its predecessor, suggesting a growing awareness about the complexity of epistemological beliefs. Even though, it is difficult to know which framework most accurately depicts the reality. This is mainly because epistemological beliefs are impossible to measure definitively; further, each framework supports different instrumentation choices.

Despite their differences, instrumentation share a general reliance upon inference. In a review of the literature conducted by Briell, Elen, Verschaffel, and Clarebout (2010), it was apparent that researchers commonly infer epistemological beliefs from (a) peripherally related conceptions, (b) problem-centered reasoning, and (c) meaning making of salient experiences or decisions. Some concern has been expressed over what constitutes a suitable inference. Instruments by Kuhn et al., (2000) and Hallett, Chandler, and Krettenauer (2002) support inferences based on respondents' reasoning of conflicting claims about everyday issues, while other researchers have argued that inferences should be reserved for the reasoning of controversial issues about which experts disagree (see Wood, Kitchener, \& Jensen, 2002). Hofer and Pintrich (1997) expressed concern over the Learning Environment Preferences instrument by Moore (1989) for making inferences based on preferences for the learning environment. Difficulties with current approaches have surfaced. Namely, common survey measures have increasingly come under criticism (Clarebout, Elen, Luyten, \& Bamps, 2001; Hofer \& Pintrich, 1997; Maggioni, Riconscente, \& Alexander 2006) and the findings of studies in terms of development can be confounding. For instance, despite modeling similar trajectories, some studies find a fair percentage of middle school participants (e.g., Krettenauer, 2005; Mason \& Scirica, 2006) and younger (Kuhn et al., 2000) are at the uppermost levels of development, while in other studies graduate (e.g., Dale, 2005) and doctorial (e.g., Friedman, 2004) students do not perform beyond intermediary levels. As Chandler, Hallett, and Sokol (2002) phrase it, "The bad news is that these more or less identical claims about the supposed course 
of epistemic development are all made about research participants of wildly different ages" (p. 146). Inferential methods are requisite, and the challenges part-and-parcel, because of how epistemological beliefs are fundamentally conceived.

While theoretical frameworks vary with respect to cognitive form and cognitive range, the conceived cognitive status of epistemological beliefs has not changed. Since they were initially investigated by Perry (1970), epistemological beliefs are generally assumed to be implicit. The implicit nature is sometimes evident in the labels given to these beliefs: "epistemic assumptions" (e.g., Eigenberger, Critchley, \& Sealander, 2007; King \& Kitchener, 2004), “epistemological assumptions” (e.g., Baxter Magolda, 2004; Granello, 2002), “epistemological forms" (Lovell \& Nunnery, 2004), “implicit epistemologies” (Pirttillä-Backman \& Kajanne, 2001). It is also apparent in researchers' descriptions of these beliefs. For instance, Ricco (2007) and Ricco and Rodriguez (2006) refer to personal epistemology as naïve or intuitive beliefs about the nature of knowledge and learning. Paulsen and Feldman (2005) describe epistemological beliefs as systems of implicit assumptions and beliefs. SchommerAikins (2004) uses the nomenclature epistemological beliefs because, in paraphrasing Pajares (1992), beliefs are thought to be less dependent on reason and evidence than one may think of knowledge advancements. Instead, epistemological beliefs are "predominantly unconscious" (Schommer, 1994, p. 316) and are thought to "innervate almost every aspect of an individual's day-to-day lives" (Schommer, 1994, p. 293). Under leading conceptualizations, the researcher is left with the difficult task of accurately identifying and interpreting the visible manifestations of implicitly held epistemological beliefs.

While we have no basis to disagree with existing literature that epistemological beliefs are mainly implicitly held, thus inferential methods necessary, we wonder whether it is possible to better our inferences. The obvious answer, due to their complexity, is that mixed methodologies are warranted. Pajares (1992) summarized the measurement of beliefs as something "that can only be inferred from what people say, intend, and do" (p. 316). Of the three, it is clear that what participants have to say, at least explicitly, has been unduly neglected. The reasons are understandable: Firstly, as Buehl and Alexander (2006) note, “... cognitive researchers have long appreciated that there is more to one's knowledge than can be put into words or can be called to mind" (31). Meaning, we should not expect explicit accounts to provide a complete picture of participants' epistemological beliefs. Secondly, Hofer and Pintrich (1997) remind us that the epistemological beliefs of participants are probably not as 
well organized as the epistemological beliefs of professional philosophers. Thus, explicit accounts would likely be a bit disjointed. Thirdly, researchers are cautious about the ability of students to express their views about concepts that are so abstract (e.g., Elen \& Lowyck, 1999; Rosenberg et al., 2006). Acknowledging all of the above, this should not be taken to mean that what participants can call to mind is irrelevant. If there is wisdom in Pajares advice, then inferences may be substantially bettered if they were based on a combination of what is said, intended, and acted.

Clearly, one step toward this measurement ideal would be to investigate methods of accessing what individuals can call to mind. The task is aptly described by Buelh and Alexander (2006, p. 31), "Part of the dilemma for knowledge researchers is finding creative and effective ways to bring individuals' knowledge to the surface and to allow thoughts or understandings to be shared in natural and meaningful ways." Instead of asking participants to state their epistemological beliefs in words - which is probably more in line with what Pajares (1992) had in mind by "say" - we wondered whether we could ask them to draw "knowledge." The technique, once perfected, could be combined with other interpretive measures to enhance inferences of students' epistemological beliefs.

The idea of using drawings as an instrument to gain insight into students' epistemological beliefs is inspired by research dating back to the mid 50s. In 1957, Mead and Métraux used drawings to unravel students' beliefs about scientists. Using a similar approach, Picker and Berry (2000) used drawings to investigate students' images of mathematicians. McDonough (2002) developed a procedure known as PPELEM (Pupil Perceptions of Effective Learning Environments in Mathematics) to gain insight into what children conceive to be scaffolds for learning mathematics. In this procedure, students are asked to draw and describe a favorable situation for learning mathematics. Drawings have also been used to investigate students' misconceptions about certain mathematical and physical concepts. For instance, in 1992, Vosniadou and Brewer used drawings - combined with interviews - to gain insight into students' views of the earth. Research on teacher development also integrated drawings as a means to investigate preservice teachers' identities and practices (Hancock \& Gallard, 2004; Swennen, Jörg, \& Korthagen, 2004; Weber \& Mitchell, 1996). Murphy, Delli and Edwards (2004) compared drawings of good teaching by primary students and pre-service and inservice teachers in order to identify differences in the characteristics they attribute to good teaching. In each case, drawings were found to be a valuable tool for accessing participants' 
(mis)conceptions. Likewise, we presume drawings can be a valuable tool to researchers interested in epistemological beliefs.

Drawings have a number of important advantages when it comes to ascertaining epistemological beliefs. For instance, drawings can reveal light nuances and ambivalences within one's belief system. According to Hancock and Gallard (2004), drawings provide a rich source of information because they include settings, arrangements in physical space, objects, action, and a reflection of the mental images one has. In addition, drawings conceivably enable students to convey their beliefs in more open and inventive ways than ordinarily permitted by structured questions and Likert scales. Unlike questionnaires, respondents do not simply agree or disagree with a statement. The technique does not prompt participants to choose a specific direction, as is often criticized when leading questions are given. While drawings have been mainly used with children in order to compensate for articulation difficulties, we are applying the technique to university students for parallel reasons. Drawings may provide a unique and valuable route of expression even for the older participant who might find it difficult to express such abstract beliefs in verbal or written words articulately.

Moreover, as an open approach, it provides the researcher an opportunity to step back from existing theory, somewhat. By asking participants to draw "knowledge," we are presuming the following: a) that definitions of knowledge are the core aspect of epistemological beliefs research, b) that epistemological beliefs are domain general to some extent (i.e., drawings refer to knowledge in general), and c) that drawings are one potential way of accessing epistemological beliefs. However, the technique does not assume which aspects of the definitions (i.e., dimensions) are relevant or how they develop. Hence, we believe drawings may be one interesting and insightful avenue for coming to know students' epistemological beliefs.

We are aware of only a few studies (e.g., Alexander \& Dochy, 1995; Maggioni et al. 2006) that employ drawings to elicit knowledge-related beliefs. In these studies, graphicrepresentation options and the option to make one's own drawing were used to sort out sociocultural differences between conceptions of knowledge and conceptions of belief. The approach taken in the studies reported in this article is different from the just mentioned studies mainly because illustrations are not used to reveal the conceived relationship between knowledge and a related concept, but to access how knowledge itself is conceived. 
A series of three studies is described below for which drawings are explored for measuring students' epistemological beliefs. In Study 1, drawings alone are analyzed. The technique is further explored in accompaniment with verbal and written explanations in Studies 2 and 3 , respectively.

\section{Study 1}

The first study aimed at exploring the potential of using drawings as a method for accessing students' epistemological beliefs. We are interested to know what beliefs about knowledge are reflected in their drawings. In order to detect these beliefs, an important aspect pertained to the development of a coding scheme for categorizing students' drawing of knowledge.

\section{Method}

Participants.

Two-hundred-sixteen, first-year, educational-science students participated in the study. Participation resulted in two credit-related points for an introductory course on "learning and instruction." On average students were 19-years old (ranging from 18-21), with a majority being female (94\%).

\section{Instrument and Procedure.}

Twenty students at a time participated in the data-gathering. Students were given a white sheet of paper and asked to draw "knowledge." They were instructed to make their drawings in such a way as to clarify what knowledge is for someone who does not understand words, such as an alien. The drawings were anonymous. Students were explicitly told to work individually and reminded that drawing skills were not at all to be worried about. Given that we were interested in what they were thinking spontaneously students only received five minutes to draw knowledge. After five minutes, all drawings were collected by the researcher. The researcher walked around the room to prevent students from looking at their neigh- 
bor's drawing. When students were finished, they were told that an explanation for the study would be given during the final class of their course.

Analysis.

To process the collected data, a bottom-up approach was adopted. The drawings were randomly divided among three researchers with each researcher getting one-third of the drawings. Each researcher individually grouped the drawings by considering similarities and differences. Afterwards, the groups were compared, discussed, and a tentative categorization system was jointly devised (Round 1).

Through a "constant comparative method" (grounded theory; Miles \& Huberman, 1994) a first group of codes was generated. After discussion the most important grouping criterion had been the location of knowledge. Is knowledge located within an individual, outside an individual or both within and outside an individual? The first category labeled Internal entities contains drawings of knowledge as something internally located within the individual. Students in this group typically draw a person with thought bubbles or an enlarged head containing "knowledge." This knowledge is expressed by symbols, words, or pictures in the mind. Figure 1 shows a prototypical example of this category where letters, mathematic symbols, and pictures are connected to each other in the thought bubbles coming from an individual's mind. The second category referred to as External objects draw knowledge as something external to the individual (see Figure 2 below). Drawings of students in this group often depict books, computers, or authorities. The third group is referred to as Combination of internal entities and external objects, because the drawings are of both internal entities and external artifacts or other persons. In Figure 3 below, the book and computer represent the external sources, while the brains refer to the internal aspect. These drawings can be interpreted in one of two ways. It could be mean that knowledge is something located in a person's mind and in external entities or, alternatively, it could mean that knowledge is located internally, but acquired from external entities. Some of the drawings could not be categorized in the above mentioned groups. Rather than a static image they portrayed an event or a series of events. In this final group of drawings knowledge gets represented as a Process, something that dynamically occurs between a person and her environment. Drawings in this category often contain arrows indicating that something enters the head of a person and something 
leaves the head, and that this process recurs, often in a cyclic process. In Figure 4, knowledge is created and shaped dynamically as one goes about repairing a flattened bicycle tire.

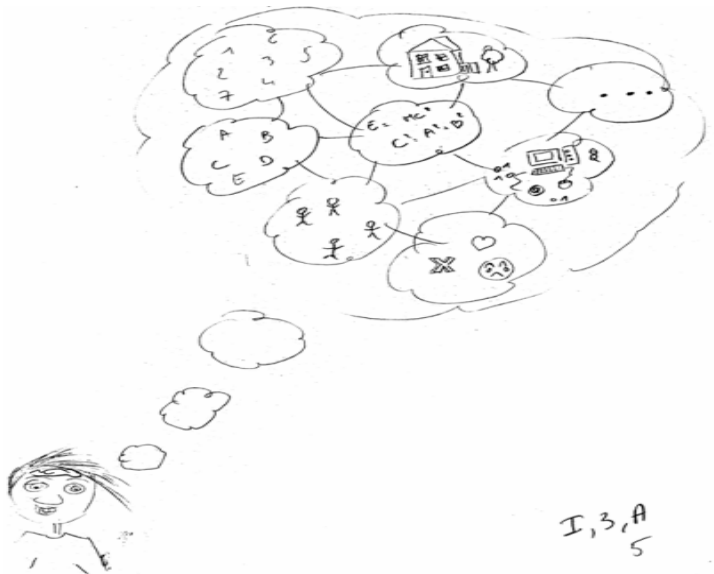

Figure 1. Internal entities

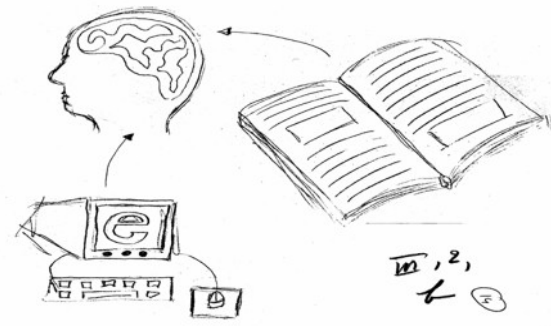

Figure 3. Combination internal entities/external objects

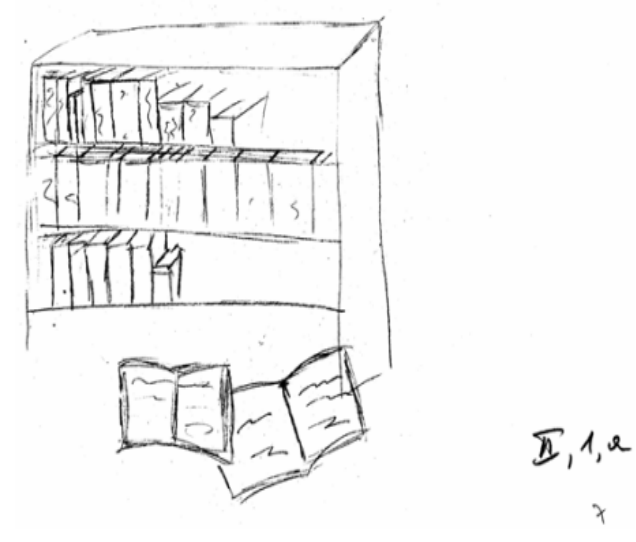

Figure 2. External objects

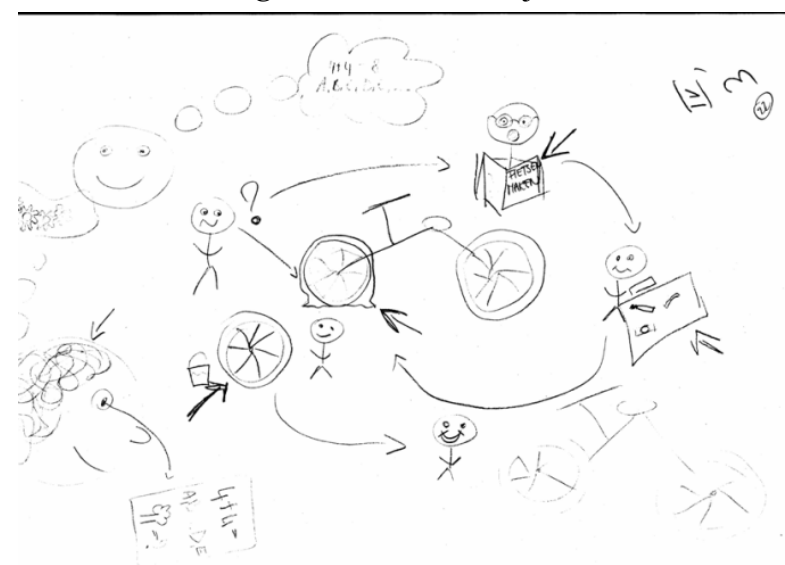

Figure 4. Process

In order to get a more fine-grained understanding of the beliefs that were represented in the drawings and to acknowledge the diversity within each group, subcategories were developed within each group. Knowledge as Internal entities was further differentiated based on the nature of the entities. A number of students draw formal knowledge located in the mind, such as numbers, mathematic equations, ABC's. Other students seem to hold a more encompassing view, also depicting experiences or feelings, for instance, by drawing hearts. Finally, some students leave the content unspecified, drawing scribbled lines, question marks, or a light bulb in the head of a person. Knowledge as External objects could be differentiated on a second level as material (e.g., books, computers, school) or material and authority figure (e.g., textbook and teacher). Drawings depicting knowledge as a Combination of internal entities and external objects could be differentiated further based on the indicated interaction between them. Some students depicted no interaction between internal entities and external 
objects, whereas others used arrows to show one-way interaction or two-way interaction. When participants drew knowledge as a Process, that process can have an antecedent, a consequence, or both. In Figure 4, the antecedent to having knowledge is the dilemma of having a flattened tire and the consequence of gaining knowledge is its repair.

In view of checking the reliability of the categorization, three researchers (two involved in the Round 1) individually re-categorized all the drawings after six months (Round 2). Given that we worked with three reviewers, three kappa coefficients were calculated. We considered a kappa coefficient of .70 as high, indicating that there was agreement among the researchers (Fraenkel \& Warren, 2003).

\section{Results}

Results in this section pertain to the re-categorization after six months. As indicated, kappa coefficients were calculated. For the three reviewers, they were between .74 and .80 for the first-level categorizations and .76 and .91 for the second-level categorizations. Of the 216 drawings, only 14 drawings $(6.5 \%)$ could not be categorized in the system. Despite the high kappa coefficients, the three researchers indicated difficulties with categorizing drawings in the Process category. This category was looked at again by the three researchers plus an additional researcher. It became evident that it was difficult to distinguish between depictions of a process and depictions of interaction between internal entities and external objects. Hence, the Process category was deleted, as they could be re-categorized as a Combination of internal entities and external objects with either one-way or two-way interactions.

Knowledge is most frequently portrayed as Internal entities. Among these, the majority refers to formal knowledge (e.g., numbers or mathematical symbols), followed by a more encompassing belief (e.g., scenic landscape, conversations with other people, a globe), and the remaining left the nature of the internal entities unspecified. To a somewhat lesser extent, knowledge is represented as a Combination of internal entities and external objects. Within this group, the majority represents a one-way interaction between an individual and materials or different persons, followed by no interaction, and finally a limited number of students indicate a two-way interaction. Knowledge is least often portrayed as External objects. These drawings could be of material objects only (e.g., books, computers, trees, houses) or, to a 
lesser extent, material and person(s), such as a professor sitting at his desk surrounded by a library of books ${ }^{1}$. The results are summarized in Table 1 below.

Table 1. Study 1 Results of drawing categorizations.

\begin{tabular}{lll}
\hline \multicolumn{1}{c}{ Level 1 } & \multicolumn{1}{c}{ Level 2} & $\%(n)$ \\
\hline Internal entities (41.7\%; $N=90)$ & unspecified & $9.3(20)$ \\
& formal & $19.0(41)$ \\
& encompassing & $13.4(29)$ \\
\hline External objects (12\%, $N=26)$ & material & $8.7(19)$ \\
& material + person(s) & $3.2(7)$ \\
\hline Combination of internal entities & no interaction & $15.3(33)$ \\
and external objects $(39.8 \%, N=86)$ & one-way interaction & $20.8(45)$ \\
& two-way interaction & $3.7(8)$ \\
\hline Other (6.5\%) & & $6.5(14)$ \\
\hline
\end{tabular}

\section{Conclusion}

The drawings provide insight into how students conceive "knowledge". The categorization scheme provided a viable way of coding the data. On a first level, drawings could be categorized as (a) Internal entities, (b) External objects, and (c) a Combination of internal entities and external objects. Within each of these categories, more fine-grained categories at a second level could be identified. The re-categorization of the drawings supports the reliability of the system. Nevertheless, further studies are needed to check the reliability of the system for additional samples.

Concurrent validity of categorization system was not verified in this study. The studies mentioned in the introduction that have used drawings as a means to measure individuals' beliefs, always complement drawings with other methods, namely, interviews or written explanations. "In the case of illustrative images, the narrative helps to confirm the meanings of the images. With more abstract images, the narrative gives meaning to the symbols or metaphors indicated" (Thomas, Pedersen, \& Finson, 2001, p. 301). Written or oral explanations of

\footnotetext{
${ }^{1}$ A nameplate indicating "Professor" is drawn in front of the person.
} 
the drawings, for instance, might not only complement the results, but also serve as a source of triangulation for the interpretations (Murphy, et al., 2004). For instance, as previously mentioned, there are two possible interpretations for the category Combination of internal entities and external objects. Explanations for these drawings might clarify which interpretation is correct.

In Studies 2 and 3, we attempt to confirm the reliability of the categorization system with additional samples and support its validity by analyzing drawing explanations.

\section{Study 2}

The purpose of this study is to test the reliability and validity of the categorization system in Study 1. To substantiate its validity, interview explanations are examined in conjunction with the drawings to see if they alter the coding and why. We also determine what supplemental information the verbal explanations provide. The research questions are:

1. Is the categorization system devised in Study 1 reliable for interpreting the students' drawings in this study?

2. Is coding altered when explanations for the drawing are considered?

3. (If so) Why does the explanation alter the coding of the drawing?

4. What supplemental information do explanations provide?

\section{Method}

\section{Participants}

Twenty-eight instructional science master students participated. None of them participated in the first study. On average students were 20.9 years old $(\mathrm{SD}=6.8)$. Eighty-nine percent were female. Students earned one credit-related point for their participation.

\section{Instrument and Procedure}

Students worked individually. When entering the room, they were asked to take a seat and then given a blank sheet of paper. Similar to Study 1, they were asked to draw "knowledge" in such a way that someone not knowing words could understand it. For the 
same reasons as in the first study and in order to ensure maximal comparability, a five-minute time limit for the drawing was imposed. Afterwards, each student was asked by the researcher to explain her drawing. Notes of students' responses were taken.

Analysis

Research question 1: is the categorization system devised in Study 1 reliable for interpreting the students' drawings in this study?

(Round 1): A first researcher coded the drawings without explanations for Level 1 and 2 and a second researcher coded the drawings independently for Level 1 of the categorization system derived in Study 1. (The two researchers were among three coders of Round 1 in the above study.) The inter-rater reliability of two coders was calculated. The two researchers discussed all Level 1 discrepancies and jointly recoded the drawings for Level 2.

(Round 2): A third researcher (the third researcher in Round 2 of the above study) independently coded the drawings for Levels 1 and 2. His coding was then compared to the joint coding of the first and second researchers. The three researchers then discussed discrepancies.

Research question 2: is coding altered when explanations are considered?

The third researcher recoded the drawings, this time simultaneously referencing participants' explanations. His coding was then compared to the consensus previously achieved in Round 2 (by the first, second, and third coders for the drawings without the explanations).

Research question 3: why does the explanation alter the coding of the drawing?

When an explanation altered the coding, both the prior and revised coding was referenced to the drawing and explanation to understand the reasons behind the revision. 
Research question 4: what supplemental information do the explanations provide?

As original explanations were in Dutch and one of the researchers was not familiar with Dutch, all explanations were translated into English by a researcher who is native in Dutch and fluent in English. Data were then analyzed by the first author. Guided by the inductive coding technique of Strauss and Corbin (1990), translations of each explanation were reviewed line by line. Descriptive labels were generated for individual units of meaning. The labels were then reviewed and, when possible, abstract categories generated.

\section{Results}

Research question 1: is the categorization system devised in Study 1 reliable for interpreting the students' drawings in this study?

Inter-scorer agreement for Level 1 was $77 \%$ and a kappa of .71 was calculated for the first round of coding. Discrepancies were discussed and some agreements were made. For the second round, inter-scorer agreement of $89 \%$ for Level 1 and $90 \%$ for Level 2, a kappa coefficient of .86 was calculated for Level 1. Coders were able to reach a consensus on all discrepancies.

Most participants illustrate a Combination of internal entities and external objects. Within this group, the majority indicate a one-way interaction, less a two-way interaction, and just one participant no interaction. The rest of the participants drew knowledge as Internal entities. The nature of that knowledge is almost evenly left unspecified, depicted as being formal, and illustrated as being more encompassing than merely formal knowledge. No participants in this study drew knowledge as External objects. A few drawings could not be readily fitted into the categorization scheme. See Table 2 below.

Research question 2: is coding altered when explanations are considered?

An agreement of $89 \%$ for Level 1 and $88 \%$ for Level 2 was achieved; a kappa of 86 was calculated for Level 1. 
Research question 3: why does the explanation alter the coding of the drawing?

The explanation altered the coding in six cases. The reasons are threefold. Firstly, the explanation provided necessary clarification for drawings previously coded Other (i.e., drawings that could not be coded). For example, a drawing is of a book, a tree, and a diagram (see Figure 5 below). From the explanation, the book symbolizes formal/factual knowledge that one gets from school. The tree and diagram indicates that knowledge must be structured. Hence, it was remarked Combination of internal entities and external objects with one-way interaction. Secondly, the explanation provided supplemental information not contained in the drawing. For instance, the drawing in Figure 6 below is of a person thinking of a math problem and solving it. The interview indicates that she did not draw more encompassing types of knowledge because it was too difficult for her to do so. Hence, on the second level, the previous coding of formal was remarked as encompassing. Thirdly, in a couple of instances, the explanation revealed that the drawing was indeed misinterpreted. For example, Figure 7 below depicts a person with three circles in the mind. The first circle contains a formula, the second illustrates the five senses, and the third depicts two hands and a smiley face. It was interpreted as Internal entities, encompassing. According to the explanation, only the first circle refers to knowledge; the second and third refer to other concepts, skills, and attitudes, respectively, in other parts of the mind. Hence, it was re-coded as Internal entities, formal.

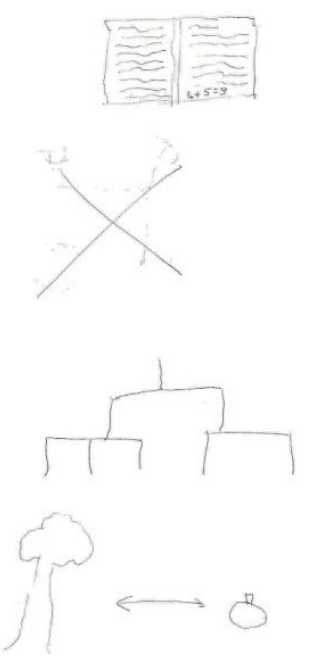

Figure 5. Example of drawing requiring clarification

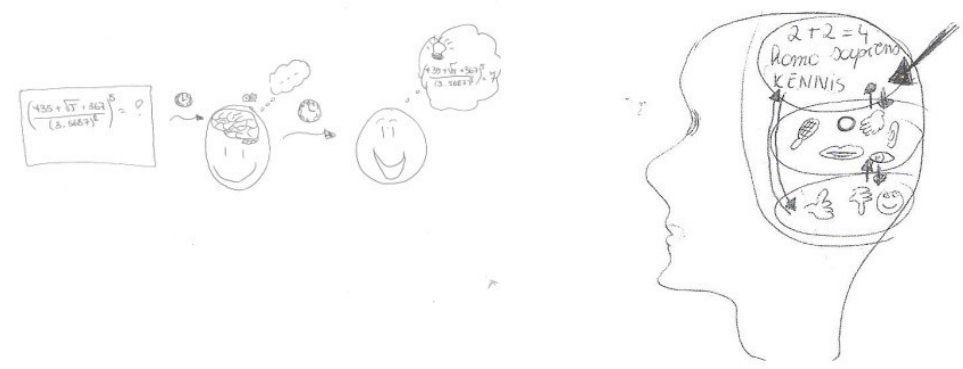

Figure 6. Example of drawing supplemented by explanation
Figure 7. Example of drawing misinterpreted before explanation 
Research question 4: what supplemental information do the explanations provide?

Explanations give us further, supportive ideas about what knowledge is to participants and how it is acquired and additional information about its structure and purposes.

\section{Knowledge defined}

Reiterating what was concluded from the drawings, the explanations reveal that knowledge is most frequently defined as cognitive structures, cognition, or something located in the mind or head of a person $(n=20)$. It is also defined as something learned $(n=6)$ or communicated $(n=5)$; something contained in books $(n=2)$, stored in computers $(n=1)$, and distinctly human $(\mathrm{n}=1)$.

\section{Knowledge acquisition}

Participants' drawings were often meant to convey details about how -from their perspective- learning occurs. As one participant explains, "A person hears things, reads things, and sees things and stores what he hears, reads, and sees in his memory. He remembers these things and can discuss them with others. Knowledge then is those things that a person has observed and stored in his memory."

The particular sources denoted as being instrumental to learning were books/reading $(n=10)$, knowledgeable people and formal education $(n=9)$, environment and experiences $(n=4)$, sensory data $(n=3)$, the internet or computer $(n=2)$, and oneself $(n=1)$. Beliefs not captured in the categorization system were that the process of acquiring knowledge involves reaching understandings, resolving a problem, or attaining new abilities $(n=8)$, it concerns inquisitiveness $(n=5)$, organization $(n=4)$, prior knowledge $(n=3)$, thinking $(n=1)$, receiving $(n=1)$, and seeking information $(n=1)$ or that learning can occur deliberately or accidentally $(n=1)$.

\section{Structure of knowledge, purposes of knowledge, miscellaneous}

Explanations sometimes mentioned the structure and purposes of knowledge as well as miscellaneous information that were predominantly not captured in the coding system. When the structure of knowledge is discussed $(n=5)$, it is almost exclusively seen as being connected 
or interrelated. However, one participant uses the metaphor of books in the library to illustrate how knowledge is stored in the mind, per subject, which does not leave the impression of a network of ideas and concepts.

Three participants shared the purpose of knowledge: Knowledge enables growth $(\mathrm{n}=1)$, decision-making $(\mathrm{n}=1)$, and, as one student says, "If someone asks you a question, knowledge enables you to answer it." Some students remind us that there are different domains of knowledge $(n=3)$, which are located in different parts of the brain $(n=1)$. Finally, a few students cite the importance of both formal and informal knowledge. As one of participants conveys it, "Knowledge about life is also a valuable form of knowledge."

Table 2. Study 2 Results of drawing categorizations

\begin{tabular}{lllc}
\hline \multicolumn{1}{c}{ Level 1 } & \multicolumn{1}{c}{ Level 2 } & \multicolumn{2}{c}{$\boldsymbol{n}=\mathbf{2 8}$} \\
\cline { 2 - 4 } & & $\begin{array}{c}\text { Drawings } \\
\mathbf{\%}(\boldsymbol{n})\end{array}$ & $\begin{array}{c}\text { Drawings w/ Oral } \\
\text { Explanations \% (n) }\end{array}$ \\
\hline Internal entities & unspecified & $10.7(3)$ & $10.7(3)$ \\
& formal & $10.7(3)$ & $10.7(3)$ \\
External objects & encompassing & $14.3(4)$ & $10.7(3)$ \\
\cline { 2 - 4 } & material & -- & -- \\
Combination of internal & material + person(s) & -- & -- \\
\cline { 2 - 4 } & no interaction & $3.6(1)$ & $53 . \overline{6} \overline{(15)}$ \\
\multirow{2}{*}{ Other } & one-way interaction & $35.7(10)$ & $10.7(3)$ \\
\hline & two-way interaction & $14.3(4)$ & $3.6(1)$ \\
\cline { 2 - 4 } & & $10.7(3)$ & \\
\hline
\end{tabular}

\section{Conclusion}

We set out to determine if the categorization scheme from Study 1 could be applied in this study and if its validity could be substantiated with verbal explanations. The three researchers were able to use the scheme to categorize the drawings and their coding demonstrated high inter-rater reliability. Hence, the scheme did prove reliable for coding the drawings in this study; however, this is a moderate success, since no drawings matched the External objects category. It is possible this is related to the fact that the students here were slightly older and further along in their studies. Our categorizations of the drawings were relatively accurate, as evident from their explanations. 
That said, we would not recommend using the instrument without triangulating the results with explanations. Explanations were considerably helpful in clarifying some of our interpretations and to grasp more sophisticated conceptions of knowledge. In the above study, it was unclear whether drawings of knowledge as Combination of internal entities and external objects meant that knowledge is located in external objects or gained from external objects. We can conclude from the explanations in this study that the latter is more frequently the case, as only a few participants defined knowledge as something to be found in external objects (e.g., something found in books or stored in computers). Explanations also indicate that students are trying to express more than our scheme captures. The scheme primarily portrays students' beliefs about the location of knowledge, to a lesser extent, what knowledge is about (i.e., formal knowledge or more encompassing), and how it is acquired (i.e., through one- or two-way interaction). The drawings with explanations provided additional information about how the learning process, the structure of knowledge, and the purposes of knowledge are understood. We can conclude that our scheme is a good starting point for understanding students' epistemological beliefs, that drawings might be a valuable tool for helping students convey those beliefs, a tool best accompanied with explanations.

\section{Study 3}

Study 3 aims to further test the validity and reliability of the categorization system for classifying students' drawings of knowledge in Study 1 and 2. Drawings are complemented with written explanations in this study. Written explanations are employed to ascertain wheter the method of drawings with explanations can be done on a larger scale. The research questions from Study 2 are reapplied in this study.

\section{Method}

\section{Participants}

Seventy educational sciences master students participated in this study. None of them participated in either Study 1 or 2. On average students were 23.8 years old $(\mathrm{SD}=5.72)$. Eighty-seven percent were female. Students received a credit-related point for their involvement in the study. 


\section{Instrument and Procedure}

The procedure was essentially the same in this study as in Studies 1 and 2, except that participants were requested to write three lines of explanation for their drawing. No interviews were conducted.

Analysis

The analyses for the four research questions are identical to Study 2.

\section{Results}

Research question 1: is the categorization system devised in Study 1 reliable for interpreting the students' drawings in this study?

The consensus between the two researchers for the first round for Level 1 was $73 \%$; a kappa of .62 was calculated. For the second round, an inter-scorer agreement of $83 \%$ for Level 1 and 77\% for Level 2 was achieved; a kappa coefficient of .78 was calculated for Level 1 .

Most participants illustrate a Combination of internal entities and external objects, evenly indicating one-way interaction and two-way interaction between internal and external components, to a lesser extent no interaction. The second largest group draw knowledge as Internal entities. Internal entities are predomantly drawn as encompassing of more than merely formal knowledge, to a lesser extent they are left unspecified, and only a couple depict them as only being formal. Two participants draw knowledge as External objects; both drawings are of material and person(s). A modest percentage of drawings could not be readily fitted into the categorization scheme. See Table 3. 
Research question 2: is coding altered when explanations are considered?

Table 3. Study 3 Results of drawing categorizations

\begin{tabular}{|c|c|c|c|}
\hline \multirow[t]{2}{*}{ Level 1} & \multirow[t]{2}{*}{ Level 2} & \multicolumn{2}{|c|}{ Study $3(n=70)$} \\
\hline & & $\begin{array}{c}\text { Drawings Only } \\
\%(n)\end{array}$ & $\begin{array}{c}\text { Drawings w/ Written } \\
\text { Explanations } \%(n)\end{array}$ \\
\hline \multirow[t]{3}{*}{ Internal entities } & unspecified & $11.3(8)$ & $14.1(10)$ \\
\hline & formal & $2.8(2)$ & $1.4(1)$ \\
\hline & encompassing & $18.3(13)$ & $15.5(11)$ \\
\hline \multirow[t]{2}{*}{ External objects } & material & -- & - - \\
\hline & $\begin{array}{l}\text { material }+ \\
\text { person }(s) \\
\end{array}$ & $2.8(2)$ & -- \\
\hline \multirow{3}{*}{$\begin{array}{l}\text { Combination of internal entities } \\
\text { and external objects }\end{array}$} & no interaction & $12.7(9)$ & $4.2(3)$ \\
\hline & $\begin{array}{l}\text { one-way } \\
\text { interaction }\end{array}$ & $15.5(11)$ & $36.6(26)$ \\
\hline & $\begin{array}{l}\text { two-way } \\
\text { interaction }\end{array}$ & $16.9(12)$ & $18.3(13)$ \\
\hline Other & & $18.3(13)$ & $8.5(6)$ \\
\hline
\end{tabular}

An agreement of $80 \%$ for Level 1 and $90 \%$ for Level 2 was achieved. A kappa of .74 was calculated for Level 1.

Research question 3: why does the explanation alter the coding of the drawing?

As in Study 2, the reasons for altered coding are threefold. Firstly, the explanation provided necessary clarification for drawings previously coded Other $(n=7)$. For instance, in Figure 8 below the drawing is of the world with eyes looking at it from different directions. The participant meant by this that one acquires knowledge from looking at the world from different perspectives. It was re-coded as Combination of internal entities and external objects, one-way interaction. Secondly, the explanation provided supplemental information to the drawing $(n=9)$. The drawing in Figure 9 (see below) depicts several external objects (e.g., radio, book, and chalkboard); the explanation is that one acquires knowledge from these sources. Previously coded as External, material and person(s), it was re-coded as Combination of internal entities and external objects, one-way interaction. Thirdly, the explanation, in four instances, revealed that the drawing was indeed misinterpreted. The drawing in Figure 10 (see below) is of a person with a thought bubble containing different objects; a backpack is 
beside the person with an arrow drawn to it from the thought bubble. It was previously interpreted as representing a Combination of internal entities and external objects with one-way interaction. The explanation indicates that the backpack is only symbolic of the knowledge one carries throughout life. Thus, it was re-coded as Internal, encompassing.

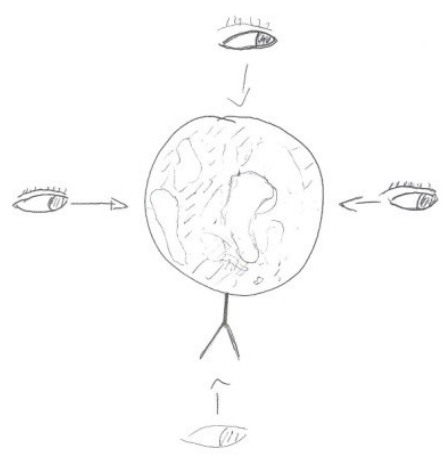

Figure 8. Example of drawing requiring clarification

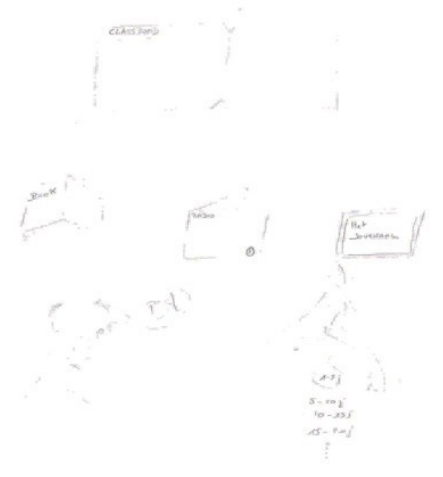

Figure 9. Example of drawing supplemented by explanation

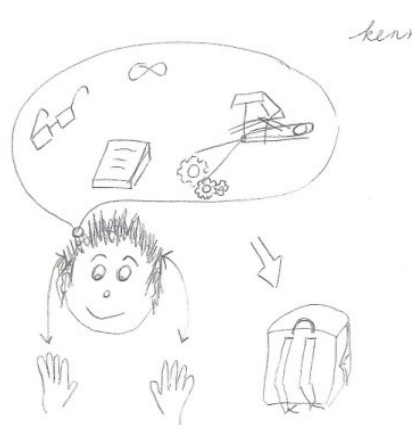

Figure 10. Example drawing misinterpreted without explanation

Research question 4: what supplemental information do the explanations provide?

Explanations provided general definitions of knowledge. The most frequent definitions reinforce what was already gathered from the drawings, that knowledge is something that is learned $(n=33)$ and cognitive structures, cognition, or something located in the mind or head of a person $(n=32)$. As one student says, "knowledge is all that we know about something; it is in our head." It is also defined as what we communicate/transfer to others $(n=11)$, information $(n=3)$, things in books $(n=2)$, facts $(n=2)$, academic subjects $(n=1)$, and our actions $(n=1)$ or feelings $(n=1)$. It is important to note here, a few participants felt it was important to provide the qualification that knowledge is many things. "Knowledge," a participant tells us, "is a lot of overlapping things, the subject of science, something found in books, something you get by asking questions, something that is positive and negative."

\section{Knowledge acquisition}

As in Study 2, frequently, participants felt it was important to convey how knowledge is acquired, especially the sources of knowledge acquisition. These include environment/experiences $(n=11)$, other people/friends/conversations $(n=13)$, books/journals/reading 
$(\mathrm{n}=10)$, knowledgeable people and formal education (elders, wise people, experts, teachers, parents, family) $(n=8)$, media (TV/radio/newspaper/magazines) $(n=7)$, self $(n=2)$, internet/computer $(n=2)$, sensory data $(n=2)$, work $(n=1)$, feelings $(n=1)$, and traveling $(n=1)$. Participants describe the acquisition process as an interaction with the environment and others $(n=13)$, as the receiving or transfer of knowledge $(n=9)$, as something that occurs with studying, thinking, reflecting, or formulating an opinion $(n=5)$, as the decoding or organizing of information or stimuli $(n=4)$, or as an act of construction $(n=4)$. The process results in the attainment of new understandings or abilities or problem resolution $(n=8)$. As a participant explains, "Knowledge is acquired by looking at the world from different perspectives in order to try and understand it." A fair number of participants mention the importance of prior knowledge $(n=8)$ and open mindedness $(n=4)$, that knowledge acquisition does not occur solely in formal settings $(n=4)$, is a never-ending process $(n=4)$, and that knowledge accumulates with age $(n=5)$. Few or less emphasize the relevance of motivation, emotions, curiosity, attentiveness, information seeking or that knowledge acquisition occurs by doing and is shaped by ones personality, perception, and experience.

\section{Structure of knowledge, purposes of knowledge, miscellaneous}

Only one participant portrays knowledge as a collection of concepts while not conveying their relatedness. The rest who touched on the structure of knowledge emphasized its interconnectedness $(n=13)$, some explaining that connections improve with time and experience $(n=4)$. For instance, a student tells us, "All knowledge is connected. When you are knowledgeable about a certain area of knowledge, you can easily draw the links."

Explanations relay the purposes of knowledge as enabling activity $(n=4)$, living $(n=3)$, problem solving $(n=3)$, understanding $(n=2)$, growth $(n=1)$, and socialization $(n=1)$; it is something that makes you think $(n=2)$, enriches your life $(n=3)$, and shapes your perception $(n=1)$.

A number of participants commented on the activation of knowledge $(n=5)$, activated as the situation demands or, because knowledge is related, when we think of one concept related concepts are also activated. "In the brain," a participant describes, "there are cluster of words, things, or etc. that are related. As soon as we think of one, the others that are related will be activated." 
Students' comments indicate that they are not oblivious to the quality of knowledge. Participants refer to indicators of quality, such as that we do not get lost $(n=1)$, we are able to resolve a problem $(n=1)$, or we are able to do something with the knowledge $(n=1)$. Other participants relay that the process of knowledge acquisition includes "questioning," "editing," or "trial and error" $(n=3)$.

\section{Conclusion}

We set out to further determine if the categorization scheme from Study 1 could be reliably applied in this study and if our categories were valid. Once again, the three researchers were able to use the scheme to categorize the drawings and their coding demonstrated high inter-rater reliability. The External objects category disappeared, yet again, once explanations were considered, suggesting this may not be a common understanding of knowledge, at least not among older university students. The validity of the categorizations was substantiated by examining the drawings in conjunctions with students' explanations for them. That said, explanations were invaluable in clarifying and supplementing our interpretations. They offer additional details about the learning process and the structure, purposes, quality, and activation of knowledge. This study further supports the conclusions of the last study, that drawings may be an invaluable entry to students' beliefs about knowledge when accompanied by explanation and that our categorization scheme is useful for interpreting them.

\section{Discussion}

We were interested in whether drawings would provide a unique, open opportunity for students to express their epistemological beliefs. The results are promising in the sense they suggest a range of beliefs, particularly concerning the location, types of knowledge, and acquisition of knowledge, which we were able to categorize in a reliable manner and substantiate with explanations. Hence, we believe the drawing instrument utilized is a promising tool for exploring and gaining entry to epistemological beliefs.

Notwithstanding, drawings have obvious disadvantages. Namely, it is time consuming to categorize them. Additionally, students might not be able to draw some of their beliefs 
about knowledge. Drawings might be conducive to certain views on the concept of knowledge and not compatible with other more sophisticated views. As a student frankly puts it, "Actually, you cannot draw knowledge; it is just an act of desperation." Although, it was explicitly mentioned that students' drawing skills would not be judged, one can still wonder, whether students drew knowledge according to what they were able to draw rather than how they actually view knowledge. Just as we have argued that some students may lack the necessary articulation skills for interviews, one could make the parallel argument that some students lack the necessary drawing skills to convey their views about knowledge through drawings. In four instances, students plainly commented that they did not draw something because they did not know how (e.g., newspaper, children playing, a person gaining knowledge from conversing with others). Because of this, we find it essential that the technique of using drawing be accompanied with oral or written explanations. The explanations need not only serve as a source of triangulation for interpretations of the drawings, but can also serve as an excellent entry into a meaningful conversation with the participant about what knowledge and knowing are. Further, drawings - even with explanations - are not a replacement for other methods; the technique presents a perspective that should be complemented with other types of approaches. McDonough (2002) stressed the importance of including drawings in a repertoire of methodologies in order to allow for a diverse representation of individuals' beliefs.

There are obvious limitations to the studies conducted. Since we were interested in what students were thinking spontaneously about "knowledge", we had imposed a fiveminute time limit, which may have placed undue stress on the participants and had the unfortunate effect of constraining their drawings, possibly resulting in rather "simple" representations of knowledge. Participants were allotted three lines for their written explanations, which is rather short considering the abstract nature of the concept. Further, the explanations were translated to English before they were analyzed, though the translator was native to Dutch and fluent in English, arguably it would have been better to analyze the data in Dutch first as to prevent any loss of meaning. Further, the analysis of supplemental information provided by explanations (i.e., Research Question \#4 in Studies 2 and 3) did not meet the same standard of objectivity, as only one researcher analyzed this data. Notwithstanding, we are confident that other raters using the same protocol would draw similar conclusions. It is also imperative that our results be compared with other sample populations. For instance, does the External objects category reappear with younger participants? And, more importantly, our participants, due to their studies in instructional science, are rather experts in the field, 
especially the master students in Studies 2 and 3. Thus, it is imperative that the instrument be investigated with participants who are not familiar with the concept of knowledge. Finally, as we stated at the onset, we believe other types of assessments are necessary to insure the inferences we make about participants' epistemological beliefs are apt and accurate.

A very basic question was raised about our work that deserves some attention: what is actually being measured? The above studies ask participants to draw "knowledge" and (in Studies $2 \& 3$ ) explain that drawing. In the opinion of the person who made the comment, it represented investigations into the "semantic space" of the word "knowledge." In other words, knowledge is an abstract term that has more than one culturally accepted and promoted definition. In this case, students are not sharing their own ideas abstracted from reflecting on their own mental creations, but instead are retelling what they have been told. This interpretation is somewhat Wittgensteinian, that is, individuals are brought up in a society to understand that there are acceptable ways of using a word. By defining a word such as "knowledge," students would thus be revealing their "form of life," the socio-cultural world of their upbringing. This line of reasoning has merit. Hence, it is no surprise that some students would define knowledge as information, as the distinction is not always made by the public. It also fits with the remark of a participant who drew books to represent knowledge. His stated reason for doing so was that books are the stereotype of knowledge. At the same time, we would argue that an abstract word, such as knowledge, has many acceptable, competing definitions. As a few of our students in Study 3 pointed out, knowledge can mean many things. We expect that individuals to some extent choose the usage that suits. Hence, when we ask a student to draw "knowledge," we might suppose she is giving the definition(s) she prefers within the parameters of the "language games" she knows. That may mean a participant realizes the word "knowledge" is used to describe the happenings in one's mind and, hopefully, has tried to make sense of those happenings. The comment raised is precisely why stated beliefs should be triangulated with other types of measures. It also implores the need for further theory and research as to the role a person's environment has on shaping his/her epistemological beliefs.

As already said, drawings are advantageous for being an open technique. Dimensions, the relevant aspects of one epistemology, are one area for which the openness of the approach could be beneficial. In their extensive review of the literature, Hofer and Pintrich (1997) proposed four dimensions: Certainty of knowledge (ranging from conceptions of knowledge be- 
ing fixed to being tentative and evolving), Simplicity of knowledge (ranging from conceptions of knowledge as discrete pieces of information to highly interrelated concepts), Source of knowledge (ranging from conceptions of knowledge being derived from external authorities to conceptions of self as knower), and Justification for knowing ("how knowledge claims are evaluated, including the use of evidence, the use they make of authority and expertise, and their evaluation of experts" [p. 120]). Each was determined to be common to psychological and philosophical treatments of epistemology. It is interesting, however, to consider what dimensions are explicitly relevant to students. In our studies, the location of knowledge and the process of acquiring knowledge are frequently evident and, to a lesser extent, the structure, purposes, activation, and quality assurance of knowledge. Three of these overlap with those suggested by Hofer and Pintrich. Namely, the structure of knowledge is analogous to the Simplicity of knowledge and the location and quality assurance of knowledge have ties to the Source of knowledge and Justification of knowledge, respectively. The Source of knowledge mainly depicts the locus of control in the process of knowledge acquisition whereas our participants are describing where knowledge can be found and the mediums of acquiring it. The locus of control was only sometimes evident in students' explanations for their drawings. The Justification of knowledge and the quality of knowledge, both identify that some knowledge constructions are superior to others. Therefore, to some extent, the dimensions relevant to existing research were also relevant to our participants, while other dimensions (i.e., the purposes and activation of knowledge) are not common to the field and suggest new avenues for research. On the other hand, the dimensions consistently relevant to researchers are not consistently relevant to students when they draw knowledge. Hence, if the aim of the research were to access traditionally researched dimensions then more structured instruments would be required.

The above observation has consequences for future research. We envision drawings as a unique, prospective measure of one component of what Pajares (1992) would call a suitable inference, what individuals have to say about knowledge, which could be combined with other instruments (measuring intentions and acts pertaining to the nature of knowledge and knowing) to contribute to better inferences of epistemological beliefs. However, the open nature of the drawing instrument utilized does not readily lend itself to being coordinated with other component measures. This means that the method of asking students to draw "knowledge" is in all likelihood best suited for exploratory purposes. This should not be taken to suggest the research reported here is irrelevant to the research community. One question 
that has plagued the field is whether beliefs about learning should be included in conceptualizations of epistemological beliefs. Hofer and Pintrich (1997) argued against doing so based on philosophical and psychological treatments of the construct. However, from an open, empirical perspective, our results indicate that when students define "knowledge," they quite naturally tend to discuss its acquisition, such as the places where it occurs and the people who enable it, that it involves prior knowledge, can occur deliberately or accidentally, and so forth. Caution is warranted, as one explanation for this finding is that our participants were all educational science students. It should also be considered why dimensions do not have universal appeal to students. For instance, most of the students who mentioned the organization of knowledge had rather sophisticated views regarding it. Could it be that some individuals have more sophisticated beliefs in certain dimensions because they have contemplated them? If so, it urges educators to look for opportunities that might stimulate students to think about their epistemological beliefs in explicit terms. For instance, students might be encouraged to think about the justication of knowledge in the context of procedures for grading their work. Namely, are there reasons why the teacher insists on well-thought, supported answers to her questions? In essence, open drawings not only suggest new avenues for research, but can also contribute to theoretical issues.

Because the findings should ideally be triangulated with other types of measures, we are hesitant to draw extensive conclusions about results or implications of this study. That said, we suppose that some drawings and their explanations are better. We assume, for instance, drawings of knowledge as something internally located and gained through two-way interaction with the physical and social environment are more preferable than drawings of knowledge as something existing in books or as something in the mind received from authoritative sources. Such differences could be related to development. For instance, the External objects category disappeared in Studies 2 and 3 where the participants are older and further along in their studies. It is alarming that some students would portray knowledge as something that purely involves formal education (i.e., formal). This would suggest disconnect with their personal lives. The number of students to draw knowledge in this way decreased from Study 1 to Studies 2 and 3, suggesting, once again, a developmental issue. This finding may be related to the finding of Maggioni and colleagues (2006) that some students view knowledge as something scientific and academic related while beliefs are seen as something socially related and personally relevant. It is left to future research to determine whether the differences in students' drawings and explanations are developmental or whether such differ- 
ences relate to students' thinking and learning. In view of this, it seems essential that samples with participants from different age groups are investigated and that future research also considers the impact of contexts on represented epistemological beliefs. Ultimately, future investigations must determine whether the types of differences we observed in participants' epistemological beliefs affect, directly or indirectly, students' learning performance.

\section{References}

Alexander, P. A., \& Dochy, F. J. (1995). Conceptions of knowledge and beliefs: A comparison across varying cultural and educational communities. American Educational Research Journal, 32, 413-442.

Baxter Magolda, M. B. (1992). Knowing and reasoning in college: Gender-related patterns in students' intellectual development. San Francisco, CA: Jossey-Bass.

Baxter Magolda, M. B. (2004). Evolution of a constructivist conceptualization of epistemological reflection. Educational Psychologist, 39, 31-42.

Belenky, M. F., Clinchy, B. M., Goldberger, N. R., \& Tarule, J. M. (1986). Women's ways of knowing: The development of self, voice and mind. New York, NY: Basic Books.

Bendixen, L. D., \& Hartley, K. (2003). Successful Learning with Hypermedia: The Role of Epistemological Beliefs and Metacognitive Awareness. Journal of Educational Computing Research, 28, 15-30.

Briell, J. E., Elen, J., Verschaffel, L., \& Clarebout, G. (2010). Personal epistemology: Nomenclature, conceptualizations, and measurement. Manuscript submitted for publication.

Buehl, M. M., \& Alexander, P. A. (2006). Examining the dual nature of epistemological beliefs. International Journal of Educational Research, 45, 28-42.

Cano, F. (2005). Epistemological beliefs and approaches to learning: Their change through secondary school and their influence on academic performance. British Journal of Educational Psychology, 75, 203-221.

Chandler, M. J., Hallett, D., \& Sokol, B. W. (2002). Competing claims about competing knowledge claims. In B. K. Hofer, \& P. R. Pintrich (Eds.), Personal epistemology: The psychology of beliefs about knowledge and knowing (pp. 145-168). Mahwah, NJ: Lawrence Erlbaum Associates, Inc.

Clarebout, G., Elen, J., Luyten, L., \& Bamps, H. (2001). Assessing epistemological beliefs: Schommer's questionnaire revisited. Educational Research and Evaluation, 7, 53-77. 
Dale, J. L. (2005). Reflective judgment: Seminarians' epistemology in a world of relativism. Journal of Psychology and Theology, 33, 56-64.

Elen, J., \& Lowyck, J. (1999). Metacognitive instructional design. Journal of Structural Learning and Intelligent Systems, 13. 145-169.

Eigenberger, M. E., Critchley, C., \& Sealander, K. A. (2007). Individual differences in epistemic style: A dual-process perspective. Journal of Research in Personality, 41, 3-24.

Fraenkel, J. R., \& Wallen, N. E; (2003). How to design and evaluate research in education ( $5^{\text {th }}$ ed.). New York: McGraw-Hill inc.

Friedman, A. A. (2004). The relationship between personality traits and reflective judgment among female students. Journal of Adult Development, 11, 297-304.

Granello, D. H. (2002). Assessing the cognitive development of counseling students: Changes in epistemological assumptions. Counselor Education and Assumption, 41, 279-293.

Hallett, D., Chandler, M.J., \& Krettenauer, T. (2002). Disentangling the course of epistemic development: parsing knowledge by epistemic content. New Ideas in Psychology, 20, 285-307.

Hammer, D. (1994). Epistemological beliefs in introductory physics. Cognition and Instruction, 12, 151-183.

Hammer, D., \& Elby, A. (2002). On the form of a personal epistemology. In B. K. Hofer, \& P. R. Pintrich (Eds.), Personal epistemology: The psychology of beliefs about knowledge and knowing (pp. 169-190). Mahwah, NJ: Lawrence Erlbaum Associates.

Hancock, E. S., \& Gallard, A. J. (2004). Preservice science teachers' beliefs about teaching and learning: The influence of K-12 field experiences. Journal of Science Teacher Education, 15, 281-291.

Hofer, B. (2000). Dimensionality and disciplinary differences in personal epistemology. Contemporary Educational Psychology, 25, 378-405.

Hofer, B. K., \& Pintrich, P. R. (1997). The development of epistemological theories: Beliefs about knowledge and knowing and their relation to learning. Review of Educational Research, 67, 88-140.

King, P. M., \& Kitchener, K. S. (1994). Developing reflective judgment: Understanding and promoting intellectual growth and critical thinking in adolescents and adults. San Francisco, CA: Jossey-Bass.

King, P. M., \& Kitchener, K. S. (2004). Reflective judgment: Theory and research on the development of epistemic assumptions through adulthood. Educational Psychologist, 39, $5-18$. 
Krettenauer, T. (2005). The role of epistemic cognition in adolescent identity formation: Further evidence. Journal of Youth and Adolescence, 34, 185-198.

Kuhn, D. (1991). The Skills of Argument. Cambridge, England: Cambridge University Press.

Kuhn, D., Cheney, R., \& Weinstock, M. (2000). The development of epistemological understanding. Cognitive Development, 15, 309-328.

Lodewyk, K. R. (2007). Relations among epistemological beliefs, academic achievement, and task performance in secondary school students. Educational Psychology, 27, 307-327.

Louca, L., Elby, A., Hammer, D., \& Kagey, T. (2004). Epistemological resources: Applying a new epistemological framework to science instruction. Educational Psychology, 39, $57-68$.

Lovell, C. W., \& Nunnery, J. (2004). Testing the adult development Tower of Babel hypothesis: Homogeneous by Perry position collaborative learning groups and graduate student satisfaction. Journal of Adult Development, 11, 139-150.

Maggioni, L., Riconscente, M. M., \& Alexander, P. A. (2006). Perceptions of knowledge and beliefs among undergraduate students in Italy and in the United States. Learning and Instruction, 16, 467-491.

Mason, L., \& Scirica, F. (2006). Prediction of students' argumentation skills about controversial topics by epistemological understanding. Learning and Instruction, 16, 492-509.

McDonough, A. (2002). PPELEM: A simple way to learn about your children and inform your teaching of mathematics. Australian Primary Mathematics Classroom, 7(3), 1419.

Mead, M., \& Métraux, R. (1957). Image of the scientist among high-school pupils. Science, $126,384-390$.

Miles, M. B., Huberman, A. M. (1994). Qualitative Data Analysis: An expanded sourcebook ( $2^{\text {nd }}$ ed.), London:Sage.

Moore, W. S. (1989). The Learning Environment Preferences: Exploring the construct validity of an objective measure of the Perry scheme of intellectual development. Journal of College Student Development, 30, 504-514.

Murphy, P. K., Delli, L. A., \& Edwards, M. N. (2004). The good teacher and good teaching: Comparing beliefs of second-grade students, preservice teachers, and inservice teachers. The Journal of Experimental Education, 72, 69-92.

Pajares, F. (1992). Teachers' beliefs and educational research: Cleaning up a messy construct. Review of Educational Research, 66, 543-578. 
Paulsen, M. B., \& Feldman, K. A. (2005). The conditional and interaction effects of epistemological beliefs on self-regulated learning of college students: Motivational strategies. Research in Higher Education, 46, 731-768.

Peng, H., \& Fitzgerald, G. (2006). Relationships between teacher education students' epistemological beliefs and their learning outcomes in a case based hypermedia learning environment. Journal of Technology and Teacher Education, 14, 255-285.

Perry, W. G. (1970). Forms of intellectual and ethical development in the college years: A scheme. New York, NY: Holt, Rinehart \& Winston.

Phan, H. (2008a). Multiple regression analysis of epistemological beliefs, learning approaches, and selfregulated learning. Electronic Journal of Research in Educational Psychology, 14, 6(1), 157-184.

Phan, H. (2008b). Exploring epistemological beliefs and learning approaches in contexts: a sociocultural perspective. Electronic Journal of Research in Educational Psychology, 16, 6(3), 793-822.

Picker, S. H., \& Berry, J. S. (2000). Investigating pupils' images of mathematicians. Educational Studies in Mathematics, 43, 63-94.

Pirttilä-Backman, A-. M., \& Kajanne, A. (2001). The development of implicit epistemologies during early and middle adulthood. Journal of Adult Development, 8, 81-97.

Ricco, R. B. (2007). Individual differences in the analysis of informal reasoning fallacies. Contemporary Education Psychology, 32, 459-484.

Ricco, R., \& Rodriguez, P. (2006). The relation of personal epistemology to parenting style and goal orientation in college mothers. Social Psychology of Education, 9, 159-178.

Rosenberg, S., Hammer, D., \& Phelan, J. (2006). Multiple epistemological coherences in an eighth-grade discussion of the rock cycle. The Journal of Learning Sciences, 15, 261292.

Schommer, M. (1990). Effects of beliefs about the nature of knowledge on comprehension. Journal of Educational Psychology, 82, 498-504.

Schommer, M. (1994). Synthesizing epistemological belief research: Tentative understandings and provocative confusions. Educational Psychology Review, 6, 293-319.

Schommer, M., Crouse, A., \& Rhodes, N. (1992). Epistemological beliefs and mathematical text comprehension: Believing it is simple does not make it so. Journal of Educational Psychology, 84, 435-443. 
Schommer-Aikins, M. (2004). Explaining the epistemological belief system: Introducing the embedded systemic model and coordinated research approach. Educational Psychologist, 39, 19-29.

Schommer-Aikins, M., Duell, O. K., \& Hutter, R. (2005). Epistemological beliefs, mathematical problem-solving beliefs, and academic performance of middle school students. The Elementary School Journal, 105, 289-304.

Strauss, A. \& Corbin, J. (1990). Basics of qualitative research: Grounded theory procedures and techniques. London: Sage.

Swennen, A., Jörg, T., \& Korthagen, F. (2004). Studying student teachers' concerns, combining image-based and more traditional research techniques. European Journal of Teacher Education, 27, 265-283.

Thomas, J. A., Pedersen, J. E., \& Finson, K. (2001). Validating the draw-a-science-teachertest checklist (DASTT-C): Exploring mental models and teacher beliefs. Journal of Science Teacher education, 12, 295-310.

Trautwein, U., \& Lüdtke, O. (2007). Epistemological beliefs, school achievement, and college major: A large scale study on the impact of certainty beliefs. Contemporary Educational Psychology, 32, 348-366.

Vosniadou, S., \& Brewer, W. F. (1992). Mental models of the earth: A study of conceptual change in childhood. Cognitive Psychology, 24, 535-585.

Weber, S., \& Mitchell, C. (1996). Drawing ourselves into teaching: Studying the images that shape and distort teacher education. Teaching and Teacher Education, 12, 303-313.

Wood, P., Kitchener, K., \& Jensen, L. (2002). Considerations in the design and evaluation of a paper-and-pencil measure of epistemic cognition. In B. K. Hofer, \& P. R. Pintrich (Eds.), Personal epistemology: The psychology of beliefs about knowledge and knowing (pp. 277-294). Mahwah, NJ: Lawrence Erlbaum Associates, Inc. 